\title{
Comparison of Four Natural Ventilation Systems in a Mediterranean Greenhouse
}

M. Coelho, F. Baptista and V. Fitas da Cruz

Universidade de Evora/ICAM, Departamento

de Engenharia Rural, Núcleo da Mitra

Apartado 94, 7002-554 Évora

Portugal

\author{
J.L. Garcia \\ Universidade Politécnica de Madrid \\ ETSIAgronomos, Departamento de \\ Ingeniería Rural, 28040 Madrid \\ Spain
}

Keywords: natural ventilation, greenhouse, modelling

\begin{abstract}
Ventilation is one of the most important tools for controlling the greenhouse climate, influencing the environmental conditions such as temperature, humidity and carbon dioxide concentration, which affect the development and production of the crop. Natural ventilation is the result of the action of two natural forces, wind and thermal buoyancy. The main objectives of this study were to: 1 ). compare the behaviour of internal air parameters such as air temperature and humidity in a greenhouse with different management of natural ventilation and 2 ). calibrate and validate a climatic model. The study was based on experiments carried out in a greenhouse located at the ETSIA-Universidad Politecnica de Madrid, with floor area of $132 \mathrm{~m}^{2}$. The greenhouse was equipped with roof and side vents along the entire length. Four different systems $(S)$ were studied, both roof and side openings $\left(S_{1}\right.$, $\left.A_{1}=21.3 \mathrm{~m}^{2}\right)$ and only roof openings $\left(S_{2}, A_{2}=12.3 \mathrm{~m}^{2} ; S_{3}, A_{3}=7.9 \mathrm{~m}^{2}\right.$ and $S_{4}, A_{4}=4.4$ $\mathbf{m}^{2}$ ). External and internal climatic parameters, such as air temperature, relative humidity, solar radiation and wind speed were measured and recorded using a data logger. All the data were recorded during several days for the different systems. Data of internal air temperature and water vapour pressure difference were analysed and compared between the different systems. In this study, ventilation rates were calculated using a model based on wind and buoyancy forces, assuming that total ventilation is due to the combined effect of both natural forces. Ventilation rates were then related to internal air conditions. Temperature differences between inside and outside varied within a range of $3.3{ }^{\circ} \mathrm{C}\left(\mathrm{S}_{1}\right)$ and $10.6{ }^{\circ} \mathrm{C}\left(\mathrm{S}_{4}\right)$, presenting an inverse proportionality to the ventilation area. The vapour pressure difference presented the highest value $(0.111 \mathrm{kPa})$ for $S_{2}$ and the lowest $(0.011 \mathrm{kPa})$ for $S_{3}$. A climatic model, based on energy and mass balances, allowing the prediction of internal air temperature and relative humidity, was calibrated and validated for the different ventilation systems. Partial data were used to calibrate the model and another set of data from different periods was used for model validation. Measured and predicted data were comparatively close.
\end{abstract}

\section{INTRODUCTION}

Production in greenhouses allows the manipulation of the way that crops are grown, by changing production and environmental control techniques. Ventilation is a technique used to control temperature, humidity and air composition. The engineering of environmental control in greenhouses is complex due to time delays in the system. Covering materials are usually very thin and transparent to allow solar radiation to enter, but this permits those changes in external conditions, such as outside temperature and wind, which rapidly affect internal conditions. In natural ventilation the location and type of the greenhouse, location of ventilation openings and climatic characteristics (wind velocity, wind direction and temperature) all have influences on ventilation rates. Zhang et al. (1989) have shown that increasing roof ventilation area will increase ventilation rate and Papadakis et al. (1996) reported more efficient ventilation when both roof and side openings are utilised.

Proc. IS on Greenhouse Cooling

Ed. B.J. Bailey

Acta Hort. 719, ISHS 2006 